\title{
CONFIGURAÇÕES DO DESENVOLVIMENTO EM DUAS NOVAS REGIÕES AUTOMOBILÍSTICAS: Sul Fluminense e Camaçari (BA)
}

\author{
DEVELOPMENT CONFIGURATIONS \\ IN TWO AUTOMOTIVE REGIONS: \\ Sul Fluminense and Camaçari (BA)
}

\author{
João Assis Dulci*
}

\begin{abstract}
Resumo
A partir da década de 1990, o Brasil assistiu a uma nova onda de instalações industriais estrangeiras em seu território. Com base em protocolos de atração, isenções e demais incentivos fiscais e locacionais, uma nova geografia do setor automotivo se desenhou no Brasil. Se num primeiro momento percebeu-se uma desconcentração industrial, no médio prazo, quando estados e municípios esgotaram suas capaci-dades de renúncia, e os benefícios infraestruturais voltaram a ter relevância na escolha das montadoras, as opções pela localização final de novas indústrias passaram a se repetir. No entanto, algumas das regiões beneficiadas pelo aporte de novas indústrias já abrigavam importantes parques industriais, o que nos leva a refletir sobre a real participação da indústria automotiva no desenvolvimento regional. Este trabalho visa, portanto, compreender a importância da indústria automotiva para o desenvolvimento de duas regiões que, até a década de 1990, não abrigavam plantas automobilísticas: o Sul Fluminense e Camaçari, na Região Metropolitana de Salvador. A partir de dados do Ministério do Trabalho e Empre-go e do Ministério do Desenvolvimento, Indústria e Comércio, busca-se mensurar a parcela de investi-mentos, renda e empregos que a referida matriz produtiva carreou para cada região, de modo a respon-der à questão sobre sua importância como vetor de desenvolvimento regional, jogando luz sobre os des-dobramentos desse processo.

Palavras-chave: Desenvolvimento regional. Indústria automobilística. Sul Fluminense. Camaçari (BA).
\end{abstract}

\begin{abstract}
Since the 1990's, Brazil has watched a new influx of foreign plants in its territory. Based on specific pro-tocols to attract industries, and also on tax exemptions and tax breaks, a new automotive industry geog-raphy has been designed in Brazil. Although in the beginning an industrial deconcentration was per-ceived, as years passed, states and municipalities exhausted its tax break capacities and, by conse-quence, infrastructural benefits were brought to light again as the most relevant attractive factors by the automotive plants. So, the implementation locations began to repeat. However, some so called green-fields already allocate important industrial clusters, which bring us to rethink about the automobile indus-trial participation on regional development. This paper aims, therefore, to understand the role that auto-motive industry began to play in regional development, specifically in two regions which did not observed automotive industries implementation until the 1990's: Sul Fluminense (Southern Rio de Janeiro State) and Camaçari, in the Região Metropolitana de Salvador (Salvador Metropolitan Region). Using Ministé-rio do Trabalho e Emprego (Labor and Employment Ministry) and Ministério do Desenvolvimento, Indústria e Comércio (Development, Industry and Trade Ministry), we measured the portion of the invest-ments which the automotive industry brought to each region, looking to respond to the issue about the current automotive industry importance as regional development carrier, enlightening the unfolding pro-cess.
\end{abstract}

Keywords: Regional development. Automotive industry. Sul Fluminense. Camaçari (BA).

\footnotetext{
* Professor do departamento de Ciências Sociais da Universidade Federal de Juiz de Fora/Brasil. Doutor em Sociologia pelo Instituto de Estudos Sociais e Políticos da UERJ/Brasil. E-mail: joaodulci@gmail.com
} 


\section{Introdução}

A indústria automotiva brasileira data do início do século XX, consolidando clusters na década de 1950 e tendo gozado de um período de reserva de mercado, com interrupções, até o processo de abertura do mercado brasileiro, nas décadas de 1980 e 1990. A partir dos anos 1990, em razão de um combinado de processos políticos e econômicos, o Brasil recebeu uma onda de investimentos para implementação de novas plantas do setor automobilístico. As condições básicas para o aporte das mesmas foram a reestruturação produtiva e a reespacialização industrial de países do centro para os países semiperiféricos, que ocupam as funções de novos mercados consumidores potenciais, plataformas exportadoras e greenfields em suas várias configurações (RADOSEVIC; ROZEIK, 2005). A expansão industrial em direção ao Leste europeu, ao México e à América do Sul fez com que se exportassem milhares de empregos para "novas" regiões automotivas (VAN TULDER; RUIGROK, 1998; COVARRUBIAS, 1998; DRUCK, 1999; GUADARRAMA; OLIVEIRA, 2001; VEGA, 2004; RADOSEVIC; ROZEIK, 2005).

A consolidação do Mercosul, as Câmaras Setoriais, o Novo Regime Automotivo e a abertura dos mercados, bem como o aumento do crédito ao consumo, a flexibilização das leis trabalhistas e os salários mais baixos do que aqueles dos países centrais foram motivos básicos para que o Brasil conseguisse atrair indústrias em competição com seus vizinhos do cone sul (ARBIX, 2006; CARDOSO, 2006). Depois da década de 1990, de fraco crescimento econômico e persistência do desemprego em patamares elevados, observou-se nos anos 2000 uma retomada do crescimento, com estabilidade monetária e aumento do número de pessoas ocupadas (tanto nos mercados formal, quanto informal) e de renda. Diante do maior poder aquisitivo e da elevação do bem-estar geral da população, e impulsionado por inúmeros incentivos fiscais, o setor automotivo foi um dos mais beneficiados pela conjuntura favorável. Porém, nos últimos anos, a trajetória ascendente da economia brasileira refreou, e os mais recentes dados sobre Produto Interno Bruto e dívida pública mostram uma situação crítica ${ }^{1}$.

Busca-se neste trabalho, portanto, responder se a indústria automotiva, mesmo diante de suas reconfigurações e reestruturações, dos inúmeros incentivos recebidos, e a despeito da crise por que passa a economia brasileira, ainda é vetor relevante para as regiões e estados que as abrigam, e tentar mensurar o tamanho de sua importância a partir de dados relacionados ao mercado de trabalho e aos investimentos proporcionados por tal matriz produtiva, como indicadores de desenvolvimento regional. O debate se constrói como atualização de algumas visões da sociologia do trabalho brasileira dos anos 1990, que lançaram olhares de desconfiança, muitas vezes com razão, sobre o modelo adotado pelo país àquele momento para atração industrial e de investimentos diretos estrangeiros (ARBIX, 2000; COMIN, 2001; RAMALHO, 2006).

1 Em 2014, o PIB brasileiro teve crescimento de 0,5\%, que antecedeu decréscimos de 3,8\% e 3,6\%, em 2015 e 2016, respectivamente, de acordo com os dados mais atuais (IBGE, 2017). A dívida líquida do setor público aumentou de $30,0 \%$ do PIB em janeiro de 2014, para 51,8\%, em janeiro de 2018, ultrapassando os $73 \%$ se considerarmos a dívida bruta (BANCO CENTRAL DO BRASIL, 2018). 
Elegemos duas regiões: o município de Camaçari, na Bahia, e a microrregião do Vale do Paraíba Fluminense, VPF, que representam bem os momentos de abertura do mercado brasileiro, uma vez que receberam o aporte de novas plantas do setor automobilístico na conjuntura de abertura dos mercados e de atração industrial do fim do século XX e de transformação do regime de acumulação do país, em consonância com as transformações da regulação capitalista levadas a cabo pelos países centrais. Além disso, são regiões com um passado industrial, correspondendo a greenfields setoriais (DULCI, 2015) em termos da matriz automotiva, mas a brownfields em termos de tradição industrial pregressa. Por fim, embora ambas as regiões sejam bastante representativas de uma conjuntura específica de atração industrial, no que se assemelham, guardam particularidades em suas trajetórias anterior e posterior à instalação das primeiras plantas de automotores, conforme mostram os dados deste trabalho. O marco temporal aqui definido é de 2007, ano em que conseguimos analisar o comportamento dos dados utilizados antes da crise internacional de 2008/2009, isolando parcialmente seus impactos, até o período mais recente de disponibilidade de informações (2015 para os dados sobre mercado de trabalho e 2017 para os dados sobre investimentos consolidados).

Adiantamos que, como num efeito de ondas ${ }^{2}$, a relevância de uma indústria de grande porte, como as indústrias automotivas o são, é mais importante para seu entorno e para municípios e microrregiões contíguas do que para escalas maiores, em função da razoável diversidade produtiva dos estados em estudo e do Brasil. Além disso, a relevância da produção de veículos e seus componentes tende a "carrear" maior grau de desenvolvimento em proporção inversa à diversidade produtiva regional, quando se teria um número mais diversificado de investimentos em uma mesma região ${ }^{3}$. Por fim, o formato do regime de acumulação e das relações de trabalho em uma dada região se mostra ligada à configuração do desenvolvimento regional no momento da atração das indústrias, sendo seu desdobramento uma consequência importante dessa configuração ${ }^{4}$. A hipótese a ser testada aqui é a de que a indústria automobilística ainda é vetor relevante para o desenvolvimento regional em greenfiels setoriais, embora o seja menos importante em escalas maiores ou em ambientes de maior diversidade produtiva, mesmo levando-se em conta as novas configurações organizacionais, mais enxutas de acordo com as características do processo de reestruturação produtiva, das quais as plantas em questão são representativas.

O conceito de desenvolvimento, aqui adotado em sua face regional, se sustenta em teorias de desenvolvimento de meados do século XX. Define-se como remoção de obstáculos ao crescimento econômico (PINTO, 1963; SUNKEL; PAZ, 1974) e superação do atraso

2 Sobre o tema e a analogia aqui adotada, ver Myrdal (1960).

3 Aqui, fazemos referência à leitura de Celso Furtado sobre desenvolvimento e expansão capitalistas, em que o autor afirma a necessidade de maior liquidez com redução de incertezas nos investimentos industriais. Com isso, uma maior diversidade de investimentos se faz relevante para que os efeitos críticos em um determinado setor não afetem toda uma cadeia, ou toda uma economia (FURTADO, 2003).

4 Fizemos o esforço de demonstrar essa hipótese em Dulci, 2015. 
(GERSCHENKRON, 1962; AMSDEM, 2001), a partir da matriz industrial (KHOTARI, 1989), posicionado num continuum em relação ao polo oposto, o subdesenvolvimento (SUNKEL; PAZ, 1974). Essas dimensões são transplantadas para escalas subnacionais em termos de atraso relativo de uma região, ou de estados, em comparação a outros, entendendo haver espaços intermediários de desenvolvimento (SUNKEL; PAZ, 1974; DULCI, 1999, 2015; FURTADO, 2003) e incorporando a dimensão espacial nos processos aqui referidos (FRIEDMAN, 1967). Ganha contornos de desenvolvimento regional quando gera efeitos propulsores para a qualificação de fatores como serviços públicos, recursos humanos, poupança e investimento, o que pode gerar progresso rápido e contínuo em um determinado local (MYRDAL, 1960), admitindo-se que o desenvolvimento regional pode ser propulsionado por grandes indústrias multinacionais, não apenas por médias e pequenas, como no debate sobre distritos de cunho marshalliano (FERNÁNDEZ et al., 2008).

Para operacionalizar essa interpretação, definimos variáveis relacionadas ao mercado de trabalho regional, bem como investimentos relativos à indústria automotiva, como indicadores de desenvolvimento regional nos moldes das teorias aqui incorporadas. Ou seja, um maior volume de investimentos, principalmente os relacionados à indústria em questão, representa inversões, crescimento e superação dos obstáculos para a consolidação da matriz produtiva nas regiões. Um eventual aumento no número de empregos significa transbordamentos dos processos de instalação das indústrias e a expansão das mesmas, e a renda dos trabalhadores, além de um indicador indireto de bem-estar e de crescimento econômico, também reflete nas economias regionais, que se postam, assim, de forma distinta, quando comparadas entre si e a outras mesorregiões 5 .

\section{A trajetória recente da indústria automotiva}

As indústrias automobilísticas brasileiras derivam de duas conjunturas que compreendem dois arranjos institucionais e regulatórios distintos. O primeiro reflete a forma de inserção do Brasil, com base em um modelo desenvolvimentista, no compromisso fordista internacional, bem como na montagem de um compromisso fordista incompleto ("fordismo periférico", conforme nomenclatura de Lipietz (1989)). A atuação do governo federal brasileiro na arbitragem dos investimentos se deu em situação de pouca autonomia, o que resultou em concentrações industriais regionais e aguçamento das desigualdades interfederativas (FURTADO, 2003).

O segundo arranjo, ou segunda conjuntura, se marca pelo avanço liberal e desmanche do "compromisso", num movimento de intensificação da transnacionalização de empregos e plantas automotivas. Países outrora semiperiféricos (caso de Japão, Coréia do Sul e os “Tigres Asiáticos”), países centrais reconstruídos no pós-Guerra e casos bem-sucedidos de social-democracia, como

5 Sobre esse ponto, comparamos as duas regiões em tela com o Grande ABC Paulista, em trabalho de 2016 (DULCI, 2016). 
Alemanha, França e Suécia, avançaram sobre mercados tradicionais do setor, principalmente a partir dos processos de reestruturação produtiva em sua indústria automobilística (BOYER; FREYSSENET, 2003).

Os Estados Unidos foram, provavelmente, o país mais atingido por esses avanços, a partir da década de 1970. A gradual perda de competitividade dos automóveis norte-americanos acelerou-se com os dois choques do petróleo, que elevaram os preços dos combustíveis fósseis (BOYER, 1990), tornando os veículos caracteristicamente de alto consumo de gasolina e diesel daquele país extremamente custosos para seus donos. Além disso, a evolução tecnológica em termos de competitividade industrial e as inovações com relação a métodos e organização fabril impuseram uma posição defensiva às tradicionais montadoras de Michigan (BOYER; FREYSSENET, 2003). A inserção gradativa de montadoras estrangeiras em solo norte-americano impeliu a competição por novas regiões do globo. A esse processo soma-se o fim da cortina de ferro (VAN TULDER; RUIGROK, 1998; RADOSEVIC; ROZEIK, 2005), questões de política imigratória e de reestruturação produtiva nas plantas centro e norte-mexicanas (COVARRUBIAS, 1998; DRUCK, 1999; VEGA, 2004) e a exploração de mercado consumidor potencialmente expansível para o continente sul-americano, o que gerou uma concentração subcontinental de plantas no Brasil, também associada a mudanças corporativas das multinacionais abrigadas nos países do cone sul (CICCOLELLA, 1992; NOVICK, 2001; CARDOSO, 2006). Em todos esses processos, no entanto, buscava-se o aumento dos lucros através de redução de gastos e aumento da eficiência produtiva, configuração facilitada pelo desenvolvimento de tecnologias informacionais, em processos de compressão de tempo e espaço (CASTELLS, 2007; HARVEY, 2008), instrumentos fundamentais para as transformações do regime de acumulação global (HARVEY, 2011) ${ }^{6}$.

A partir dos processos de reestruturação, as multinacionais do setor automotivo gestaram configurações produtivas que foram exportadas para diversos países, no espírito de ocupação de novos espaços de produção, os chamados greenfields (VAN TULDER; RUIGROK, 1998; RADOSEVIC; ROZEIK, 2005) e de redução de mão de obra, ou dos custos das mesmas. Se no Leste-Europeu e no norte do México configuram-se mais claramente casos de greenfields stricto sensu, o Brasil constitui-se num modelo híbrido, em que internamente se reproduz a dualidade brownfield $\mathrm{x}$ greenfield, embora não fique evidente que algumas das regiões escolhidas pelas multinacionais do setor sejam exatamente greenfields ${ }^{7}$. É preciso descer mais um degrau na escala, mirando as dimensões meso e microrregional, para demonstrar, como no caso do Vale do Paraíba Fluminense, que o município de Volta Redonda representa um brownfield diante de

6 Não se pretende aqui um esforço no sentido de esgotar o desmanche do compromisso fordista. Para entender tanto o desmanche nos termos regulacionistas, ou pela via marxista, ver Sassen (1988); Lipietz (1989); Boyer (1990; 1994); Harvey (1992, 2005, 2008, 2011); Dreifuss (1996); Boltanski e Chiapello (2009), dentre outros.

7 Trata-se de uma questão escalar, combinada a uma questão conceitual (DULCI, 2015). Friedman, em texto de 1967, definia greenfield a partir de um prisma de planejamento regional, como um ponto ótimo locacional para instalação de uma empresa. Scott Martin e João Paulo Veiga (2002) definem como “[...] regiões, em geral interio- 
Resende e Porto Real, greenfields. Por isso, adotamos a noção de greenfield em termos setoriais de produção, denominando tanto o sul do estado do Rio de Janeiro, quanto Camaçari, na Bahia, "greenfields setoriais" (DULCI, 2015), uma vez que a tradição industrial de ambas as regiões data das décadas de 1940 e 1970, respectivamente. Esse ponto é relevante por se relacionar com a maior dependência que o desenvolvimento do Vale do Paraíba Fluminense passa a ter da matriz automobilística, principalmente com o declínio da siderurgia na região, a partir dos anos 1990 . Tal fenômeno foi fundamental para a configuração salarial quando da instalação da Volks em Resende. Já em Camaçari, a presença dos setores químico e petroquímico forçaram a Ford a equiparar os ingressos de seus trabalhadores às empresas daqueles setores, mais altos quando comparados aos da região fluminense.

Podemos afirmar que a década de 1990 representou uma nova onda de investimentos estrangeiros no Brasil. Isso se deu basicamente pela conjunção de fatores relevantes, já fartamente apontados pela literatura especializada. As Câmaras Setoriais (mormente a Câmara Setorial da Indústria Automotiva ${ }^{8}$ ), a consolidação do Mercosul como mercado consumidor ampliado, a infraestrutura industrial, viária e portuária brasileira, superior em comparação àquelas de nossos vizinhos sul-americanos, e as medidas de internalização dos investimentos especificamente automotivos representada pelo Novo Regime Automotivo foram as grandes motivações para novos investimentos (CARDOSO, 2006). A "guerra fiscal"', definidora de uma postura do governo federal distante das disputas e reificadora de desigualdades, e os inúmeros incentivos diretos e indiretos, públicos e privados, foram os elementos que deram destino à instalação das plantas industriais (COMIN, 2001; NABUCO et all., 2002; ARBIX, 2006, etc.).

\section{Os casos e o método de análise comparativa}

Os casos aqui estudados inserem-se na expansão da esteira produtiva global, em fins de século XX. A comparação, além do exposto na introdução, também se justifica por se tratar de duas regiões com um passado industrial em matrizes diferentes da automobilística, o que permite "isolar" os investimentos automotivos dos demais setores produtivos e comparar seu comportamento com os demais, identificando em que medida a indústria automotiva se torna protagonista ou não do desenvolvimento regional. Além disso, são regiões que representam o

\footnotetext{
ranas, sem (ou com pouca) tradição na indústria manufatureira, em especial na indústria automobilística” (p.19); para Olga Firkowski, seriam regiões cujas características principais são "inexistência de tradição industrial; fraca atuação sindical; baixos salários e governos interessados em atrair investimentos estrangeiros, o que, no Brasil, se manifestou no intenso processo de concessão de incentivos fiscais e financeiros, denominados 'guerra fiscal"' (FIRKOWSKI, 2010, p. 76); Marco Aurélio Santana aponta a pouca tradição industrial e "baixa ou nenhuma densidade sindical" (SANTANA, 2010); e Kulfas et al. definem greenfields como o processo de implantação de uma fábrica, totalmente nova, com a tecnologia mais atual possível, em detrimento da estratégia de reestruturação produtiva de uma planta já existente (KULFAS et al., 2002).

8 Sobre o tema, ver: Martin (1996); Oliveira; Comin (1999); Arbix (2000); Leite (2000), dentre vários outros.

9 Para uma discussão mais aprofundada sobre o tema, ver Dulci, 2002.
} 
contexto de abertura dos mercados descrito acima, que buscou atrair plantas automobilísticas a partir de protocolos reproduzidos. Buscamos aqui analisar duas trajetórias, traçando como parâmetros comparativos, quando possível, o comportamento do emprego e dos investimentos nos estados nos quais as regiões se inserem, bem como no Brasil. O marco temporal escolhido encerra ainda um período de expansão do emprego e do mercado consumidor, incluindo o consumo de automóveis; e o período crítico mais recente. Ademais, temos uma boa medida da realidade nacional anterior à crise mundial de 2008/2009 e seus desdobramentos. Tal crise teve efeitos sobre diversos setores produtivos no Brasil, o que se percebe em alguns dos dados aqui levantados.

O Polo Industrial de Camaçari é resultado dos esforços para a redução da desigualdade de desenvolvimento regional no Brasil, a partir da Superintendência do Desenvolvimento do Nordeste (SUDENE), do Plano de Desenvolvimento da Bahia (PLANDEB) e de financiamento do Banco Nacional de Desenvolvimento Econômico e Social (BNDES), a partir do II Plano Nacional de Desenvolvimento (II PND) (MENDES, 2006; ANDRADE, 2009). Inicialmente pensado como um polo de refino de petróleo da Petrobras (à época chamava-se Complexo Petroquímico de Camaçari - COPEC), paulatinamente atraiu indústrias do setor químico (como borrachas e plásticos). Mais recentemente, iniciativas do setor farmacêutico e de química avançada foram observadas no polo, que acabou por receber, na virada do século, a planta da Ford Motors do Brasil (DULCI, 2015).

A trajetória do desenvolvimento, fortemente concentrado na Região Metropolitana de Salvador, se deu com surtos de desarranjo urbano e crescente hiato na estratificação social. A estratificação urbana da região reforça esse ponto. Altos funcionários das indústrias do Polo Petroquímico de Camaçari habitam em Salvador, enquanto os operários do chão das fábricas residem em Camaçari, Lauro de Freitas, Dias D’Ávila e Candeias, mais fortemente. O município de Camaçari divide-se em três grandes regiões: o centro, onde se concentram os camaçarienses, o Polo Industrial e o litoral, onde situam-se condomínios de luxo (CASTRO, 1988; PESSOTTI, 2010; DULCI, 2015).

A história da instalação da planta referente ao Projeto Amazon ${ }^{10}$, da Ford Motors, na Bahia, iniciou-se a partir de questionamentos feitos pelo então governador eleito do Rio Grande do Sul, Olívio Dutra, aos incentivos oferecidos pela gestão anterior, de Antônio Brito. A Ford suspendeu a construção da fábrica naquele estado. Com a reabertura da disputa, a montadora recebeu a oferta de incentivos, financiamentos, isenções e doação de terreno por parte do governo da Bahia, em negociações capitaneadas por proeminentes políticos locais, que asseguraram a aprovação da emenda ao Novo Regime Automotivo, nomeada "especial para o Norte, Nordeste

10 Amazon é o nome do projeto de implantação de uma planta Ford, no Brasil, no formato de condomínio industrial para fabricar alguns modelos de automóveis adaptados das plataformas mundiais da montadora. À época, os modelos Ka e Fiesta eram os carros-chefe do projeto (LUKACS, 2005). 
e Centro-oeste", facilitando a decisão da montadora ${ }^{11}$. A Ford de Camaçari tem capacidade de produção de 250 mil veículos/ano, e já foi identificada como a fábrica de maior produtividade da montadora no mundo.

Já o Vale do Paraíba Fluminense, microrregião composta pelos municípios de Barra Mansa, Itatiaia, Pinheiral, Piraí, Porto Real, Resende, Quatis, Rio Claro e Volta Redonda, abriga disparidades de desenvolvimento entre os municípios. Apesar disso, percebese um enorme fluxo de pessoas e relações que permitem identificar a região como um corpo integrado (IBGE, 2008). Apoiando-nos na tipologia proposta por Anssi Paasi (2000), afirmamos que o Vale do Paraíba Fluminense é uma região resultante de um processo de acumulação de capital, em decorrência da produção desigual dos lugares, mas sem uma prévia demarcação de fronteiras, o que se mostra muito claro pelos processos históricos que têm a implantação da Companhia Siderúrgica Nacional como propulsora. Também pode ser dita como uma região "historicamente construída" por inúmeros tipos de relações e um espaço de conformação de práticas sociais, institucionalizadas através de um processo pelo qual uma unidade territorial se torna uma entidade estabelecida na estrutura espacial e pode, portanto, ser identificada em termos de práticas institucionalizadas e consciência social nas esferas política, econômica, cultural e administrativa, sendo continuamente reproduzidas nessas práticas (PAASI, 2000) ${ }^{12}$.

A história produtiva do Vale do Paraíba Fluminense foi muito marcada pela Companhia Siderúrgica Nacional (CSN). Sua instalação, na década de 1940, resultou na emancipação do distrito de Volta Redonda. Em 1993, com a privatização da CSN, profundas transformações ocorreram na região. A inserção regional na esteira automobilística mundial se deu num dos primeiros esforços da "guerra fiscal", em meados dos anos 1990, quando do anúncio das intenções da Volkswagen de implantar uma fábrica de ônibus e caminhões no Brasil. O estado do Rio de Janeiro, através de uma força tarefa, e a prefeitura de Resende empenharam-se em protocolos de atração industrial, incentivos, isenções, construção de subestações de energia e infraestrutura viária para consolidar seus esforços (LIMA, 2005, RAMALHO, 2005, SANTANA, 2010, dentre outros). Pouco depois de iniciadas as operações no formato de consórcio modular da Volks Caminhões e Ônibus, em Resende, o Rio de Janeiro lançou-se na disputa por mais uma planta para a região: a PSA Peugeot-Citroën, que seria sediada pelo então distrito industrial de Porto

11 Em dezembro de 2009, uma decisão judicial condenou a Ford a pagar R \$134 milhões (em valores de 1999), por considerar que a empresa norte-americana desrespeitou o contrato firmado com o governo gaúcho. A Decisão foi contestada pelo Tribunal de Justiça do Rio Grande do Sul, que considerou a decisão como apartada de um processo mais amplo sobre o mesmo tema. No início de 2014 a decisão foi ratificada pela Justiça, com uma indenização fixada em 160 milhões de Reais (http://tjs.jusbrasil.com.br/noticias/100537209/por-nao-instalar-fabrica-no-rs-ford-econdenada-a-ressarcir-o-estado-em-mais-de-r-160-milhoes).

$12 \mathrm{O}$ mesmo não se pode dizer da Região Metropolitana de Salvador, motivo pelo qual comparamos um município (Camaçari) a uma região (Vale do Paraíba Fluminense). Isso se deve à presença na RMS não só a capital, Salvador, com economia fortemente calcada em serviços voltados para hotelaria e turismo, mas também vários municípios de seu entorno, que funcionam como um prosseguimento da capital. Em função dessa aguda polarização, optamos por analisar o município de Camaçari de forma isolada. 
Real (SANTANA, 2010) ${ }^{13}$, que resultou emancipado depois de algumas rodadas de negociações políticas, lideradas por empresários locais, tornando-se o município de maior PIB per capita do estado fluminense ${ }^{14}$.

As duas fábricas possuem trajetórias desiguais em relação ao seu potencial sucesso na região. Em função de políticas públicas voltadas para desenvolvimento tecnológico do óleo diesel brasileiro ${ }^{15}$, a Volks Caminhões e Ônibus observou queda acentuada em sua produção e em seu número de vendas por alguns anos ao longo da primeira década deste século. A PSA, também em função de oscilações estratégicas, anunciou e adiou por algumas vezes a ampliação de sua produção. No entanto, no cômputo geral, pode-se dizer não só que são fábricas consolidadas, como que tiveram efeito na geração de externalidades positivas para o Vale do Paraíba Fluminense, o que se materializa na atração de outras três novas montadoras (DULCI, 2015; 2016). Apesar do relativo sucesso corporativo, os números em relação à realidade recente dos trabalhadores não demonstram a mesma sintonia, como veremos mais adiante.

\section{Os dados}

Quando observamos a variação geral do emprego formal no Brasil, nos estados da Bahia e do Rio de Janeiro, no Vale do Paraíba Fluminense e em Camaçari, podemos perceber que as curvas apresentam comportamento semelhante (gráfico 1). A trajetória é crescente até os anos de 2013 e 2014, quando inicia uma tendência de queda (RAIS/MTE, 2007-2015). Se observarmos as linhas do VPF e do estado do Rio de Janeiro, podemos afirmar que o acréscimo de empregos formais no estado fluminense é menos intenso do que na microrregião. Fenômeno diverso ocorre quando comparamos Bahia e Camaçari. As oscilações são mais frequentes no município, ao passo que o estado apresenta uma trajetória relativamente mais robusta no sentido de incremento de empregos formais, tomando o ano de 2007 como base ${ }^{16}$. A média nacional apresenta aumento relativo de empregos formais maior do que o estado do

13 Identificamos em outro trabalho que, no caso do Vale do Paraíba Fluminense, percebe-se uma transposição da dualidade greenfield $\mathrm{x}$ brownfield para o nível microrregional, uma vez que as duas montadoras pioneiras do sul do estado recusavam quase explicitamente a contratação de mão de obra oriunda ou relacionada à CSN e seu passado sindical, ainda muito recente na região (DULCI, 2015). Ao longo da década de 2000 e 2010, mais duas montadoras instalaram-se na região, atraindo também fábricas de pneumáticos, produtos químicos, bem como fomentando a integração com um dos braços siderúrgicos da CSN, em Barra Mansa, o que fortalece nossa convicção quanto à forte integração produtiva, material e social do Vale do Paraíba Fluminense e de grande parte do Sul Fluminense.

14 Sobre o processo de negociações para emancipação do município, ver Lima, 2005.

15 A resolução 315, de 2002, do Conselho Nacional do Meio Ambiente previa a redução de material particulado no óleo diesel consumido no Brasil a partir de 2016. No entanto, uma resolução complementar, de número 403/2008 antecipou para 2012 a implementação dos óleos do tipo S-10 e S-50, o que obrigou a alterações nos processos produtivos, impactando na redução de linhas de crédito para modelos com a tecnologia anterior e consequente redução nas vendas (CONAMA, 2002; 2008).

16 É preciso considerar aqui o efeito da elasticidade de um município em comparação a um estado, o que não invalida as análises propostas. 
Rio de Janeiro, mas menor que a microrregião do Vale do Paraíba Fluminense, o estado da Bahia e Camaçari, até 2012. A partir de 2012, a tendência é de incrementos menores nos casos baianos em análise.

Gráfico 1 - Variação percentual do número de empregos formais. Vale do Paraíba Fluminense, Camaçari, Bahia, Rio de Janeiro e Brasil, 2007-2015, $(2007=100)^{17}$.

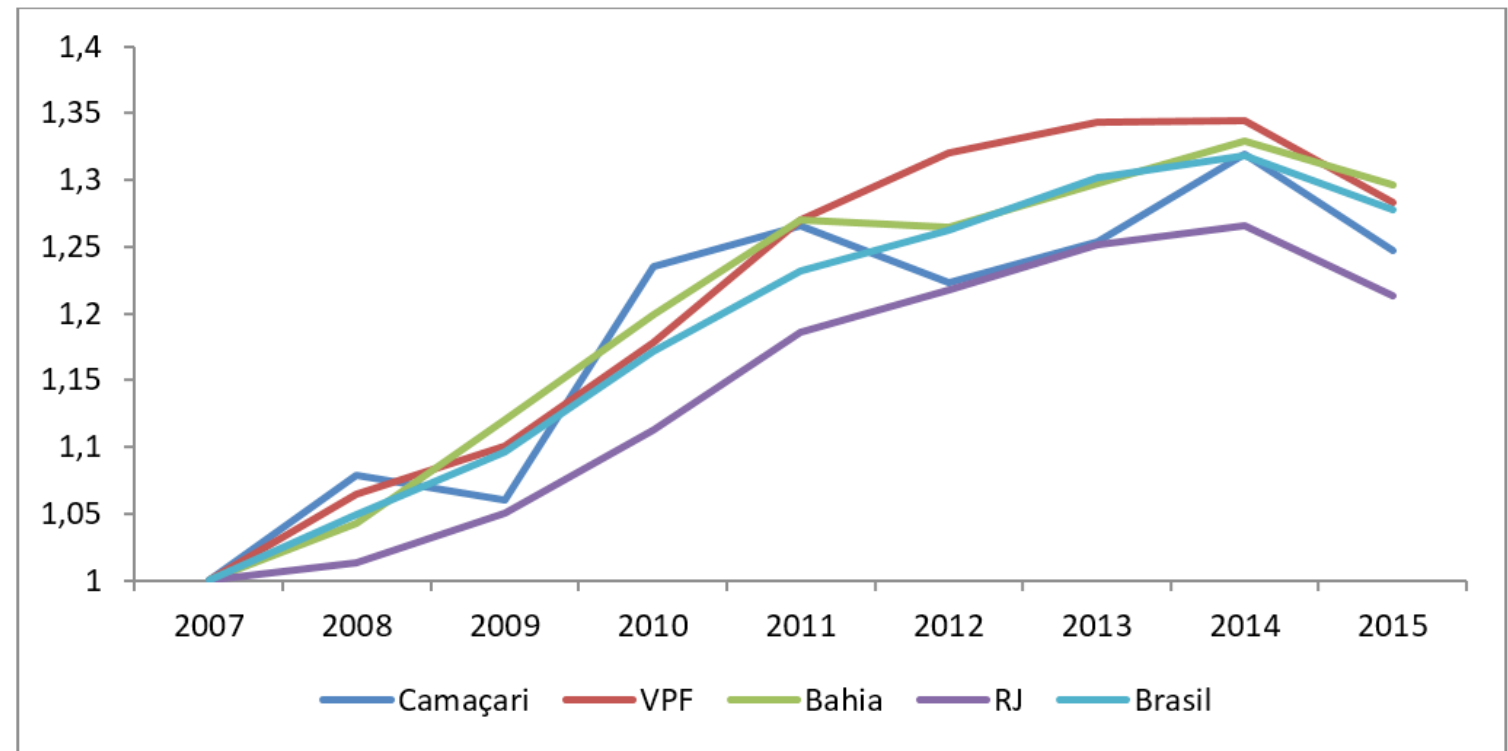

Fonte: RAIS/MTE, 2007-2015.

Ao mirarmos os rendimentos médios mensais de cada caso, temos que os ingressos de Camaçari são maiores do que nas demais comparações (gráfico 2). Os rendimentos do estado da Bahia e do Vale do Paraíba Fluminense são menores. Esse fenômeno se explica em muito pela presença das indústrias químicas e petroquímicas no Polo Industrial de Camaçari, que levaram, inclusive, a Ford Motors do Brasil a uma tentativa de equiparar seus salários para atrair mão de obra. Já no Vale do Paraíba Fluminense, a trajetória dos rendimentos acompanha o contexto negativo dos anos 1990, tendo-se "fixado" em patamares menores (DULCI, 2015; 2016). Utilizamos também as médias regionais dos rendimentos mensais de todos os vínculos formais das regiões selecionadas, de modo a termos parâmetros para compararmos com a indústria automobilística $^{18}$. Se a microrregião do Vale do Paraíba Fluminense observa rendimentos médios mensais que variam de $\mathrm{R} \$ 1.090,00$ (2009) a $\mathrm{R} \$ 1.230,00$ (2014), aproximadamente, os empregos relacionados à matriz automobilística variam de $\mathrm{R} \$ 2.080,00$ (2007) a $\mathrm{R} \$ 2.188,00$ (2014).

17 Fixa-se aqui a análise tomando o ano de 2007 como ano inicial (2007 equivalente a 100\%). Com isso, os números variam sempre em relação ao ano de 2007.

18 Excluem-se os estados da Bahia e do Rio de Janeiro desta análise, uma vez que os empregos relacionados à indústria automotiva concentram-se quase que totalmente nas regiões de Camaçari (Bahia) e do Vale do Paraíba Fluminense (Rio de Janeiro). 
Gráfico 2 - Rendimentos médios mensais dos empregos formais. Vale do Paraíba Fluminense, Camaçari, Bahia, Rio de Janeiro e Brasil, 2007-2015. Valores deflacionados pelo IPCA (2007=100).

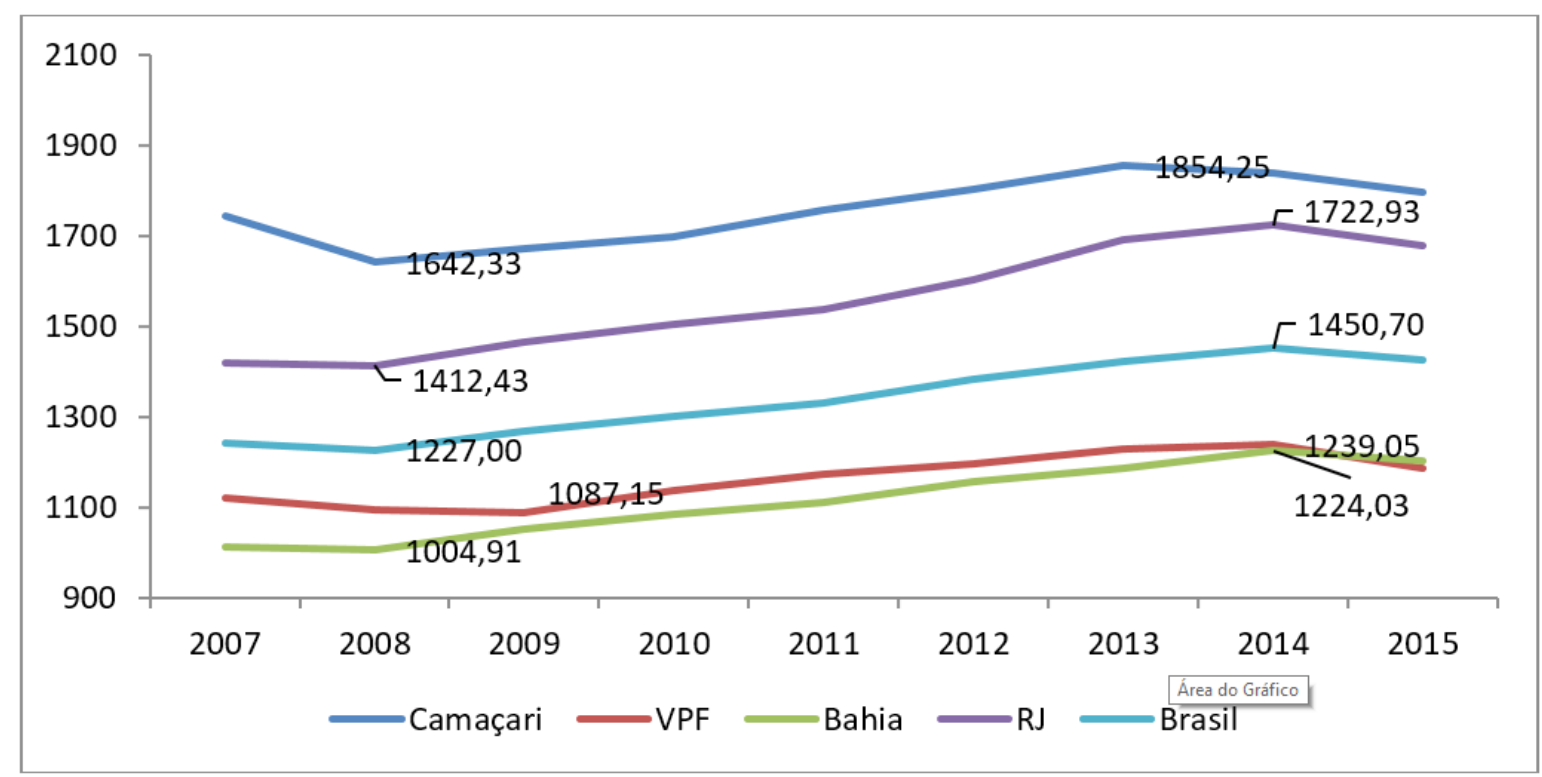

Fonte: RAIS/MTE, 2007-2015.

Chama atenção, no entanto, o declínio observado em 2015, que se deve ao agudo período crítico da economia brasileira (gráfico 3). A queda dos rendimentos, na verdade, foi a primeira a ser observada no período crítico por que passamos. Isso se deve, mormente, ao elevado grau de formalização do setor industrial automotivo, bem como à capacidade de negociação sindical das perdas salariais com a inflação. Aparentemente, essa capacidade se esgota com o risco iminente do desemprego. Em Camaçari, a ascensão da curva de rendimentos médios nos setores ligados à matriz automobilística refreou-se nos anos de 2013 e 2014, apresentando também queda em 2015. Fenômeno semelhante ocorre com a média nacional dos rendimentos relacionados à produção de automóveis e autopeças. A média camaçariense ainda é maior em quase $\mathrm{R} \$ 400,00$ do que a nacional, e em quase $\mathrm{R} \$ 700,00$, se comparada ao caso fluminense. 
Gráfico 3 - Rendimentos médios mensais dos empregos formais relacionados à produção automotiva. Vale do Paraíba Fluminense, Camaçari e Brasil, 2007-2015. Valores deflacionados pelo IPCA $(2007=100)^{19}$.

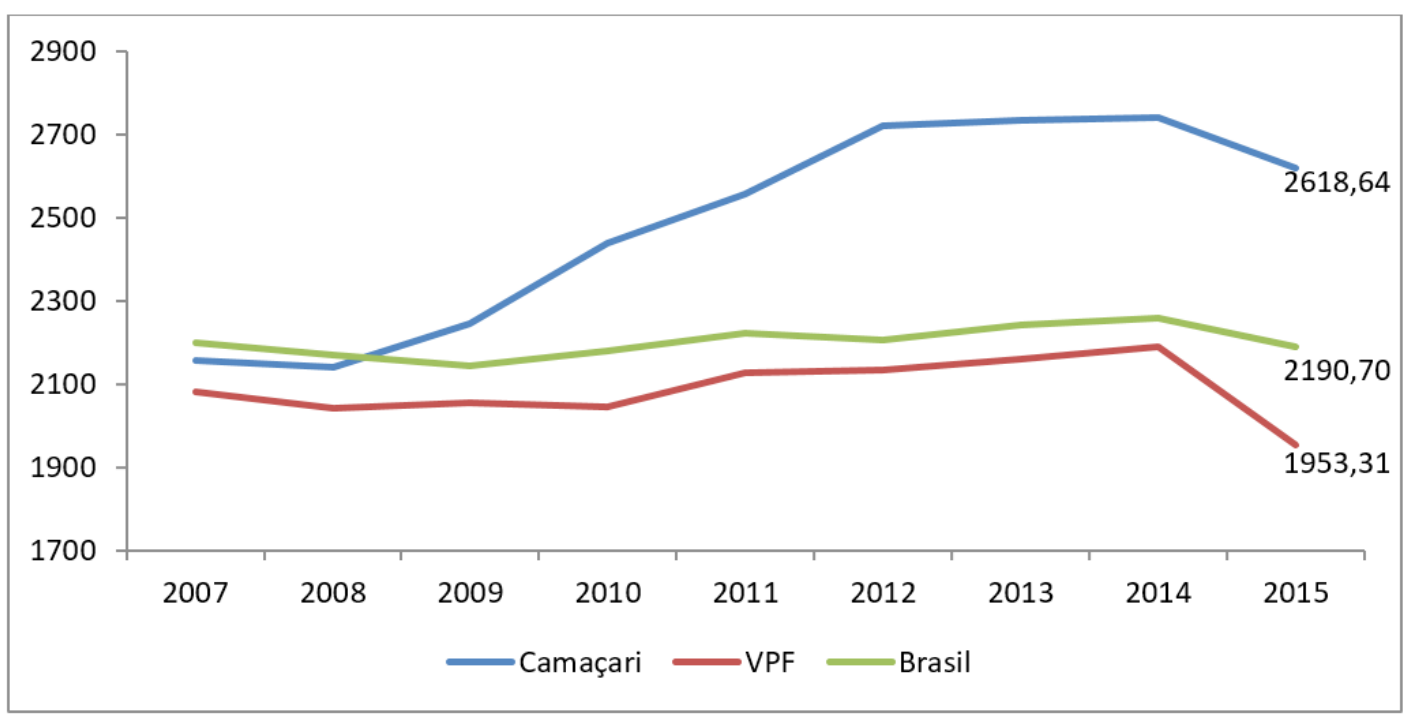

Fonte: RAIS/MTE, 2007-2015.

Com relação à criação de empregos (gráfico 4), tomando 2007 como referência, os incrementos são extremamente oscilantes na microrregião do Vale do Paraíba Fluminense. Isso se deve em parte às alterações tecnológicas na produção de caminhões, com alterações nas linhas de crédito para seus compradores, bem como à relutância da PSA Peugeot-Citroën em ampliar sua capacidade produtiva (DULCI, 2015). Ao mesmo tempo, os aumentos numéricos de empregos acompanham as instalações de novas plantas de automóveis e de pneumáticos na região.

É importante ressalvar que o incremento de praticamente $60 \%$ nos empregos ligados à matriz automobilística no VPF em 2011, em relação à 2007, segue a tendência do aumento na produção de automóveis no Brasil, bem como da expansão das iniciativas de fomento levadas a cabo pelo governo federal e pelo Banco Nacional de Desenvolvimento Econômico e Social ${ }^{20}$.

19 Para o mapeamento da cadeia automotiva brasileira, elegemos as seguintes classes de produção: Fabricação de pneumáticos e de câmaras de ar; Fabricação de automóveis, camionetas e utilitários; Fabricação de caminhões e ônibus; Fabricação de cabines, carrocerias e reboques para veículos automotores; Fabricação de peças e acessórios para o sistema motor de veículos automotores; Fabricação de peças e acessórios para os sistemas de marcha e transmissão de veículos automotores; Fabricação de peças e acessórios para o sistema de freios de veículos automotores; Fabricação de peças e acessórios para o sistema de direção e suspensão de veículos automotores; Fabricação de material elétrico e eletrônico para veículos automotores, exceto baterias; Fabricação de peças e acessórios para veículos automotores não especificados anteriormente (Classificação Nacional de Atividades Econômicas 2.0). Não estão contemplados os setores de vendas, ou recondicionamento, embora estejam inseridos na análise os grupos da indústria autopartista. Isso porque o primeiro grupo faz parte da cadeia de comércio, ao passo que o segundo contempla negócios muito pequenos e pouco elásticos à produção de automóveis novos. Por lidarmos com regiões cujos números agregados são muito distintos, optamos pela análise de dados proporcionais. Em alguns momentos, trataremos dos números absolutos. O mapeamento segue modelo de Torres e Cário, 2013.

20 Em 2013, 3,7 milhões de veículos foram produzidos ante 3,1 milhões em 2014 e 2,4 milhões em 2015. Os licenciamentos seguem a mesma tendência declinante (ANFAVEA, 2017). 
No entanto, nem a extensão recente dos incentivos parece ter sido suficiente para a manutenção do nível de emprego no Brasil. No Vale do Paraíba Fluminense, o nível de empregos formais aproxima-se do patamar de 2007. A média nacional também retraiu. Só Camaçari apresenta ainda uma trajetória ascendente, o que se explica por investimentos de fábricas de pneumáticos no Polo Industrial, além da transferência de setores das plantas da Ford do estado de São Paulo para a Bahia.

Gráfico 4 - Variação percentual do número de empregos formais relacionados à produção automotiva. Vale do Paraíba Fluminense, Camaçari e Brasil, 2007-2015 (2007=100)

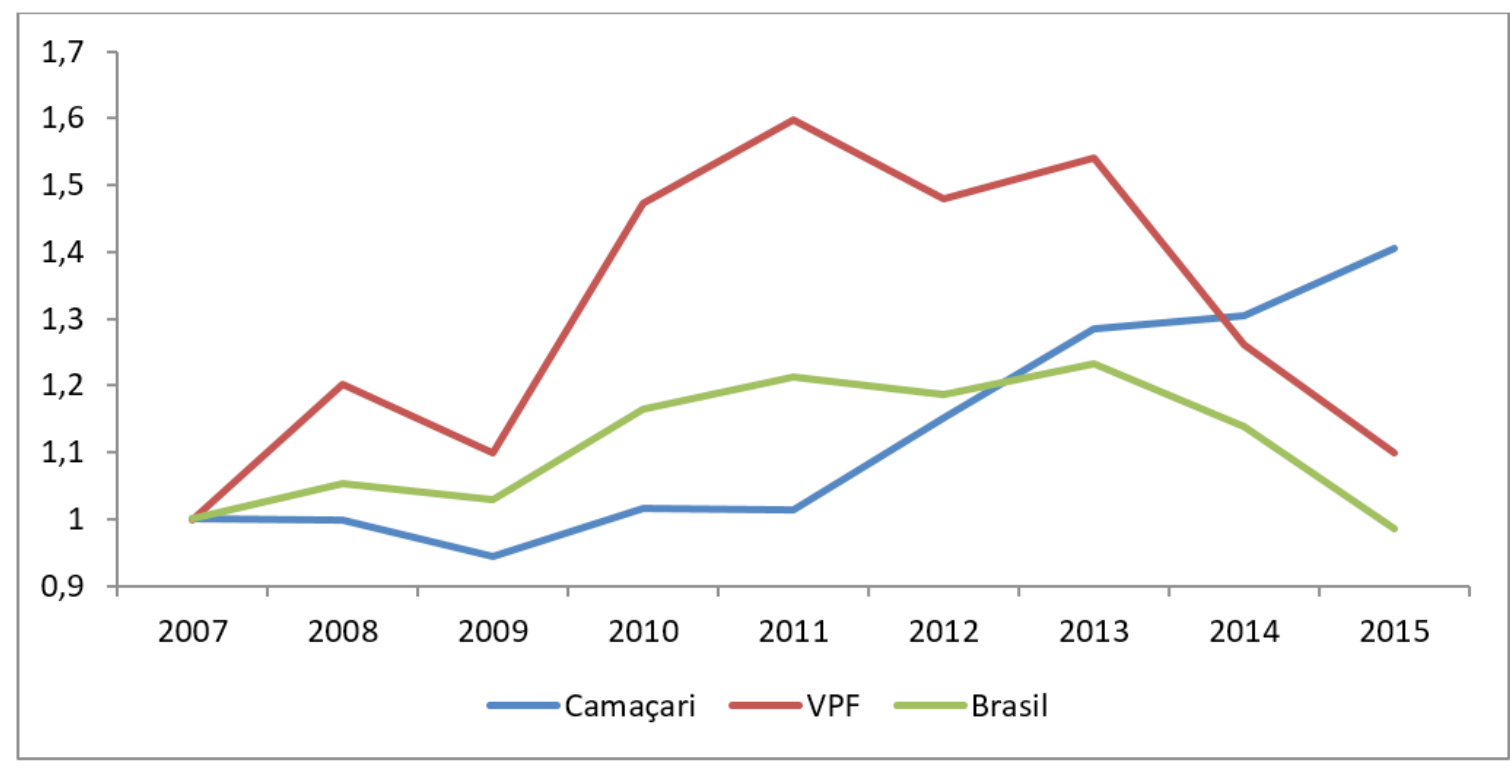

Fonte: RAIS/MTE, 2007-2015.

De modo a tentarmos avançar nas respostas à pergunta que se pôs neste trabalho, investigamos os investimentos anunciados por empresas ligadas à matriz automotiva, conforme a mapeamos aqui, compilados pelo Ministério do Desenvolvimento, Indústria e Comércio, desde 2007 até o presente. Foram 23 iniciativas na Bahia e 12 no Rio de Janeiro. Elas totalizam US\$2,5 bilhões em Camaçari e US\$6,9 bilhões no Vale do Paraíba Fluminense. No entanto, como se percebe no gráfico 5, em relação ao ano de 2007, Camaçari teve grandes saltos nos anos de 2009 e $2011^{21}$, ao passo que VPF teve uma trajetória mais suave e constante de investimentos. A média nacional de investimentos relacionados ao setor automobilístico vem declinando, o que parece corroborar a observação de que os incentivos oferecidos pelo governo federal não foram utilizados em investimentos, mas numa perspectiva de reestruturação do tipo defensiva ${ }^{22}$.

21 Os "saltos" geralmente referem-se à instalação de novas plantas industriais, o que mobiliza mais recursos. 22 Sobre o conceito, ver Ferraz et al., 1996. 
Gráfico 5 - Variação percentual do volume de investimentos anunciados na produção automotiva, Vale do Paraíba Fluminense, Camaçari e Brasil, 2007-2015 (2007=100)

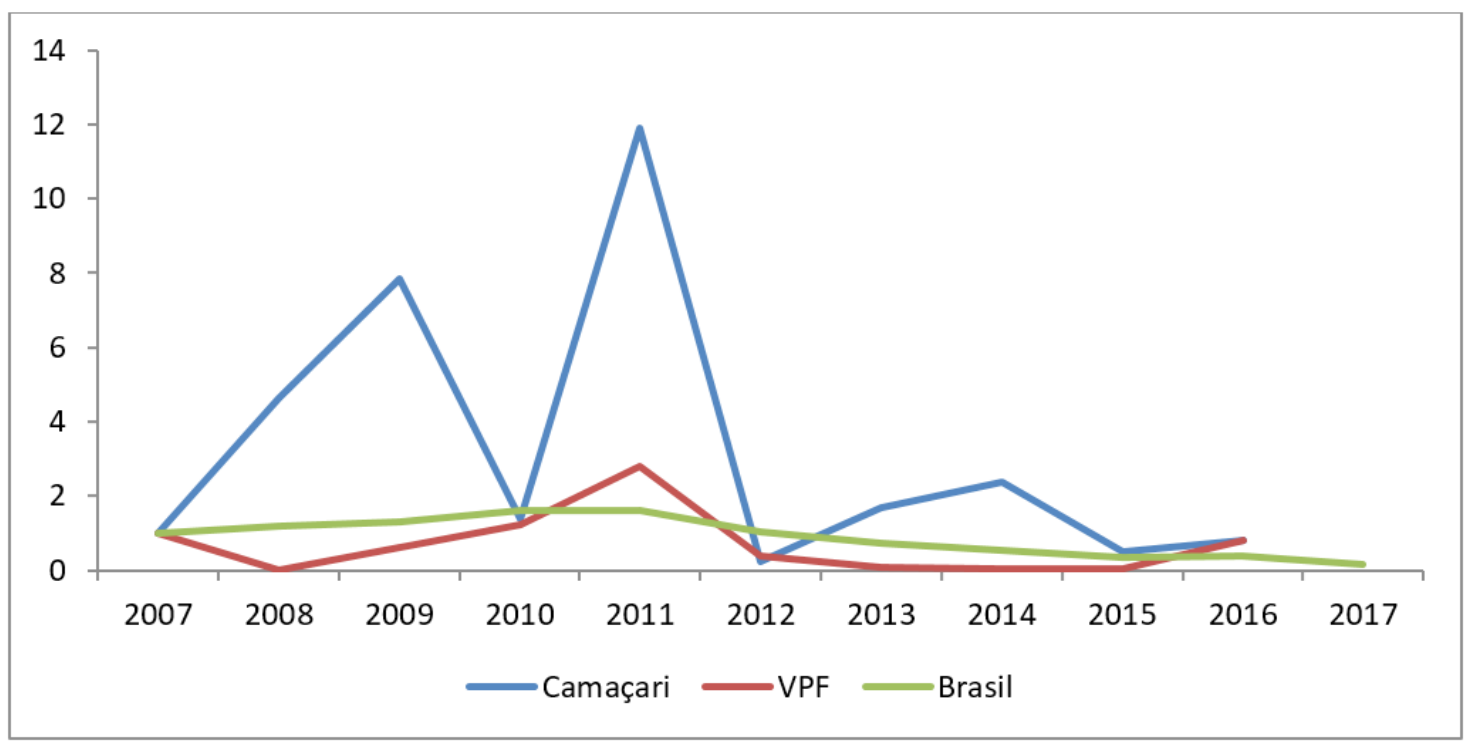

Fonte: RENAI/MDIC, 2007-2017.

Na tabela 1, apresentamos, na primeira coluna, a proporção dos investimentos do setor automobilístico de cada região em relação aos investimentos de mesma natureza em todo estado, e desses em relação ao total do país. Na segunda coluna, o percentual de investimentos no setor automobilístico em relação ao total de investimentos de cada região, de maneira a deixar clara a contribuição da cadeia automotiva no desenvolvimento recente de cada local. $\mathrm{Na}$ terceira coluna, por fim, o percentual de investimentos em cada região comparado ao total dos estados, e desses com relação ao Brasil. Os investimentos automotivos em Camaçari e no Vale do Paraíba Fluminense representam quase a totalidade da matriz produtiva em seus estados. Os investimentos automotivos em VPF representam $86,5 \%$ do total de investimentos na região, o que reforça a importância da matriz produtiva ali. Totalizam também $5 \%$ do total de investimentos no estado ${ }^{23}$. Já em Camaçari, as indústrias ligadas ao setor automobilístico foram responsáveis por $34,3 \%$ do total de investimentos. Embora seja um percentual bastante menor do que o do Vale do Paraíba Fluminense, o Polo Industrial de Camaçari é bastante mais diversificado do que no sul do estado do Rio de Janeiro, abrigando mais de 90 empresas, dentre elas uma refinaria da Petrobras e empresas a ela relacionadas. Por fim, os investimentos automotivos em Camaçari representam 5,9\% do total de investimentos anunciados para o estado da Bahia.

Tabela 1 - Percentual de investimentos automotivos comparados por escala territorial e por

23 É fundamental ressaltar aqui que, com os grandes eventos esportivos que o estado do Rio de Janeiro sediou, ele foi a unidade da federação que mais recebeu novos investimentos, mesmo se comparado a São Paulo (RENAI/ MDIC, 2004-2017). 
total de investimentos, Vale do Paraíba Fluminense, Camaçari, Bahia, Rio de Janeiro e Brasil, 2007-2017

\begin{tabular}{|c|c|c|}
\hline $\begin{array}{r}\text { Percentual de investimentos } \\
\text { automotivos em } \\
\text { comparação com os } \\
\text { investimentos automotivos } \\
\text { da escala territorial superior }\end{array}$ & $\begin{array}{r}\text { Percentual de investimentos } \\
\text { automotivos em comparação } \\
\text { com o total de investimentos } \\
\text { na região }\end{array}$ & $\begin{array}{r}\text { Percentual de investimentos } \\
\text { automotivos em comparação } \\
\text { com o total de investimentos } \\
\text { automotivos da escala } \\
\text { territorial superior }\end{array}$ \\
\hline $92,3 \%$ & $86,3 \%$ & $5,0 \%$ \\
\hline $96,4 \%$ & $34,3 \%$ & $5,9 \%$ \\
\hline $3,2 \%$ & $6,1 \%$ & $0,1 \%$ \\
\hline $9,3 \%$ & $5,4 \%$ & $0,4 \%$ \\
\hline $100,0 \%$ & $4,7 \%$ & \\
\hline
\end{tabular}

Fonte: RENAI/MDIC, 2007-2017.

Na tabela 2, temos os dados fornecidos pela Associação Nacional dos Fabricantes de Veículos Automotores para os anos em análise. Em termos de número de empregos, nota-se uma redução até os patamares do ano de 2007, tendo o pico sido atingido em 2013, com 156.970 empregados (ANFAVEA, 2017).

Tabela 2 - Número de empregos das indústrias automobilísticas brasileiras, 2007-2016 ${ }^{24}$

\begin{tabular}{lccc}
\hline Ano & Autoveículos & $\begin{array}{c}\text { Máquinas agrícolas } \\
\text { e rodoviárias }\end{array}$ & Total \\
\hline 2007 & 104.274 & 16.064 & 120.338 \\
2008 & 109.848 & 16.929 & 126.777 \\
2009 & 109.043 & 15.435 & 124.478 \\
2010 & 117.654 & 18.470 & 136.124 \\
2011 & 124.647 & 19.987 & 144.634 \\
2012 & 132.096 & 19.560 & 151.656 \\
2013 & 135.343 & 21.627 & 156.970 \\
2014 & 125.977 & 18.531 & 144.508 \\
2015 & 114.336 & 15.440 & 129.776 \\
2016 & 104.412 & 16.766 & 121.178 \\
\hline
\end{tabular}

Fonte: ANFAVEA, 2017.

24 Os dados de produção e vendas, segundo a mesma fonte, também seguem trajetória negativa (ANFAVEA, 2017). 


\section{Considerações finais}

Com este trabalho, propusemos responder à pergunta sobre a relevância da indústria automobilística nas economias regionais nas quais seinsere, diante de um cenário de transformação do regime de acumulação e das mudanças espacial e configuracional das indústrias. Com os dados levantados, demonstramos que as médias salariais do setor automotivo são maiores do que as médias salariais regionais, bem como, que o volume de investimentos anunciados pelas indústrias relacionadas à produção de veículos, instaladas e ainda por se instalar, representa uma grande fatia dos investimentos em cada região, e mesmo um percentual relevante dos investimentos de cada estado em análise. $\mathrm{O}$ momento crítico, porém, não permite afirmações definitivas. A indústria automobilística nacional, que parecia ter passado ilesa pela grave crise internacional iniciada em 2008, apresenta indicadores negativos nos últimos anos. Sua reação é a usual: demissão de funcionários, principalmente dos menos qualificados, e redução de produção em função do decréscimo das vendas, reforçando o que já havíamos verificado em outro trabalho (DULCI, 2016).

A despeito dos grandes incentivos fiscais recebidos pelas produtoras de veículos automotores, a rotina de retração do chão de fábrica segue seu curso, principalmente em regiões tradicionais, como o Grande ABC Paulista, e mesmo em "novas" regiões automotivas, como o Vale do Paraíba Fluminense. Em Camaçari, os efeitos nocivos da atual conjuntura parecem não ter tido tanto impacto ainda, embora os últimos dados não sejam conclusivos sobre uma eventual inversão de trajetória. Assim como se demonstra a ampla relevância da indústria automobilística no cenário produtivo regional, compreende-se que os impactos de uma crise no setor tendem a reverberar com maior força. A aparente "dependência" em relação ao setor em regiões como o Vale do Paraíba Fluminense (um misto de desenvolvimento "ancorado pelo Estado" com desenvolvimento privado de formato "plataforma-satélite" (MARKUSEN, 1995)), pode resultar em períodos críticos e em esvaziamentos de tipo vicioso (MYRDAL, 1960). Uma maior diversidade produtiva, como a observada em Camaçari, tende a processos críticos menos agudos, já que crises em um determinado setor não necessariamente atingem outros (FURTADO, 2003), uma vez que compõem cadeias globais de valor distintas. O exemplo do setor siderúrgico pode ser lembrado, quando enfrentou sérias dificuldades em 2009 e nos anos seguintes, contrastando com a tranquilidade com que o setor automotivo ultrapassou aquele período.

Dada a importância da indústria automotiva em economias microrregionais, apontamos para suas consequências em termos salariais e de desenvolvimento (utilizando o volume de novos investimentos como indicador), alterando, inclusive, perfis produtivos regionais: no Vale do Paraíba Fluminense, a forte dependência da região à siderurgia parece ter migrado para o setor automobilístico, pelo menos em termos de novos investimentos e de expansão da região, conforme nos mostram os dados. Esse ponto possui relação com o debate aqui proposto sobre 
brownfields e greenfields setoriais. A região fluminense passava por um contexto de declínio do setor siderúrgico, o que motivou as plantas automobilísticas a se afastarem da tradição local, inclusive no recrutamento de mão de obra (SANTANA, 2010), criando um greenfield dentro de uma região de brownfield. Efeito contrário teve a tradição industrial e sindical no caso baiano, ajudando a elevar o nível salarial dos empregados da Ford e demais indústrias relacionadas. No entanto, a formação de uma nova dependência a uma matriz que foi importante para a recuperação da região sul fluminense pode vir a ter efeito reverso, conforme o contexto oscilante aponta, mesmo que indiretamente.

A hipótese aqui proposta parece fazer sentido, quando consideramos que, mesmo com plantas enxutas e pouco empregadoras em comparação às fábricas dos anos 1970 e 1980, a indústria automobilística possui peso relevante para o desenvolvimento regional, seja num brownfield siderúrgico, seja num polo industrial com mais de noventa empresas. O esforço analítico segue, naturalmente, no sentido de reanalisar os dados aqui apresentados num futuro próximo, a saber se o país conseguirá sair da presente crise econômico-política, ou se submergirá nela, abrindo espaço para a opção de saída (HIRSCHMAN, 1973) das corporações para países vizinhos em situações mais estáveis, anulando, portanto, vantagens comparativas das quais o Brasil se valeu para a atração industrial nos últimos vinte anos.

\section{Referências}

AMSDEN, A. H. The rise of "the rest": challenges to the west from late-industrializing economies. Oxford: Oxford University Press, 2001.

ANDRADE, M.C.B. O uso do território no contexto da reestruturação produtiva: o caso do pólo industrial de Camaçari., Encuentro de Geógrafos Latino Americanos, 12., 2009, Montevideo. Anais del XII Encuentro de Geógrafos de América Latina - Resumenes. Montevidéo: Easy Plan-ners, v. 1, 2009.

ANFAVEA, Associação Nacional dos Fabricantes de Veículos Automotores. Anuário 2017. São Paulo, 2017.

ARBIX, G. Guerra fiscal e competição intermunicipal por novos investimentos no setor automotivo brasileiro. Rio de Janeiro: Instituto Universitário de Pesquisas do Rio de Janeiro, 2000.

Guerra fiscal, espaço público e indústria automobilística no Brasil. In: CARDOSO, A.; COVARRUBIAS, A.

A indústria automobilística nas Américas. Belo Horizonte: Ed. UFMG, 2006.

BRASIL. Banco Central do Brasil, Notas Econômico-financeiras para a Imprensa, Finanças Públicas, 2018. Conselho Nacional de Meio Ambiente. Resolução número 315, 2002. Conselho Nacional de Meio Ambiente. Resolução número 403, 2008.

Ministério do Desenvolvimento, Indústria e Comércio. Rede Nacional de Informações sobre o Investimento: RENAI, vários anos.

Ministério do Trabalho e Emprego. Registros Administrativos. RAIS, vários anos.

BOLTANSKI, L.; CHIAPELLO, È. O novo espírito do capitalismo. São Paulo: WMF Martins Fontes, 2009.

BOYER, R. A teoria da regulação: uma análise crítica. São Paulo: Nobel, 1990. As alternativas ao fordismo - dos anos 80 ao século XXI. In: BENKO, G.; LIPIETZ, A. As regiões ganha-

doras - distritos e redes: os novos paradigmas da geografia econômica. Oeiras: Ed. Celta, 1994.

; FREYSSENET, M. Los modelos productivos. Madrid: Editorial Fundamentos, 2003. 
CARDOSO, A. A nova face da indústria automobilística brasileira ou a tese da convergência revisitada. In: CARDOSO, A.; COVARRUBIAS, A. A indústria automobilística nas Américas. Belo Horizonte: Ed. UFMG, 2006.

CASTELLS, M. A sociedade em rede. São Paulo: Paz e Terra, v.1, 2007.

CASTRO, N. A. Novo operariado, novas condições de vida e trabalho nas fronteiras do moderno capitalismo industrial brasileiro. In: Encontro Nacional de Estudos Populacionais, 6, Olinda, Anais do VI Encontro Nacional de Estudos Populacionais. Belo Horizonte: ABEP, v.2. p. 437-482, 1988.

CICOLELLA, Pablo José. Reestructuración industrial y transformaciones territoriales: consideraciones teóricas y aproximaciones generales a la experiencia argentina. Universidad de Buenos Aires, Instituto de Geografía, Facultad de Filosofía y Letras, 1992. Disponível em http://ww2.filo.uba.ar/contenidos/investigacion/institutos/geografia/ territ4.htm. (acessado em 19/05/2017).

Conselho Nacional de Meio Ambiente (CONAMA). Resolução número 315, 2002.

Conselho Nacional de Meio Ambiente (CONAMA). Resolução número 403, 2008.

COMIN, A. "Reestruturação do Complexo Automotivo Brasileiro (Das câmaras setoriais ao novo regime automotivo)." In: OLIVEIRA, Francisco de \& COMIN, Alvaro A. Os Cavaleiros do Antiapocalipse (Trabalho e política na indústria automobilística). São Paulo, Cebrap/Entrelinhas 243, 1999.

"Verdades e mentiras sobre a onda recente de penetração estrangeira no Brasil". Indicadores Econômicos FEE 28, no. 4, 161-182, 2001.

COVARRUBIAS, A. Subsistema de empleo em México y Brasil: un modelo analítico y dos estudios de caso en la industria automotriz. Revista latino-americana de estudos do trabalho, São Paulo, ano 4, n.8, p.29-58, 1998.

Divergências convergentes na transformação das práticas de emprego - Estudos de caso da indústria automobilística no México e no Brasil. In: CARDOSO, Adalberto; COVARRUBIAS, Alex: A indústria automobilística nas Américas: a reconfiguração estratégica e social dos atores produtivos. Belo Horizonte: Ed. UFMG, 2006.

DREIFUSS, R. A. A época das perplexidades. Petrópolis: Vozes, 1996.

DRUCK, M. G. Terceirização: (des)fordizando a fábrica - um estudo do complexo petroquímico. São Paulo: Boitempo Editorial, 1999.

DULCI, J.A. Desenvolvimento regional e mercado de trabalho em perspectiva comparada: Vale do Paraíba Fluminense e Camaçari (BA). 2015. 332 fl. Tese (Doutorado em Sociologia), IESP/UERJ, Rio de Janeiro: 2015.

Novas e antigas regiões automotivas em tempos de crise: Sul Fluminense, Camaçari e Grande ABC Paulista. In: 40 Encontro Anual da Associação Nacional de Pós-Graduação e Pesquisa em Ciências Sociais, 2016, Caxambu. Anais do 40 Encontro Anual da Anpocs, 2016. p. 1-27.

DULCI, O. S. Política e recuperação econômica em Minas Gerais. Vol. 37. Belo Horizonte: Editora UFMG, 1999. Guerra fiscal, desenvolvimento desigual e relações federativas no Brasil. Revista de Sociologia e Política. o.18, p. 95-107, Curitiba, 2002.

FERRAZ, J.C.; KUPFER, D.; HAGUENAUER, L. Made in Brazil. Rio de Janeiro: Ed. Campus, 1996.

FERNÁNDEZ, V. R.; AMIN, A.; VIGIL, J. I. Repensando el desarrollo regional. Buenos Aires: Miño y Dávila Editores, 2008.

FIRKOWSKI, O. L. C. F. Considerações sobre as escalas espaciais de análise da indústria no Brasil. Revista da ANPEGE, v. 2, n. 02, p. 67-79, 2010.

FRIEDMAN, J. A general theory of polarized development, In: The ford foundation: urban and regional advisory program in Chile. Santiago: The Ford Foundation, 1967.

FURTADO, C. Raízes do subdesenvolvimento. Rio de Janeiro: Editora Record, 2003.

GERSCHENKRON, A. Economic backwardness in historical perspectives: a book of essays. New York: Frederick A. Praeger Publishers, 1962. 
HIRSCHMAN, A. O. Saída, voz e lealdade: reações ao declínio de firmas, organizações e estados. São Paulo: Editora Perspectiva, 1973.

HARVEY, D. A condição pós-moderna. São Paulo: Ed. Loyola, 1992.

A produção capitalista do espaço. São Paulo: Annablume, 2005.

Neoliberalismo: história e implicações. São Paulo: Loyola, 2008.

O enigma do capital. São Paulo: Boitempo, 2011.

IBGE. Regiões de influência das cidades. Rio de Janeiro: 2008.

Diretoria de Pesquisas. Coordenação de Contas Nacionais. Produto Interno Bruto, 2017.

JUSBRASIL. Por não instalar fábrica no RS, Ford é condenada a ressarcir o Estado em mais de R\$ 160 milhões. Portal Jusbrasil, (s/d). Disponível em <http://tj-rs.jusbrasil.com.br/noticias/100537209/por-nao-instalar-fabrica-no-rs-ford-e-condenada-a-ressarcir-o-estado-em-mais-de-r-160-milhoes.>. Acesso em 15 nov. 2011.

KOTHARI, R. Rethinking Development: In Search Of Humane Alternatives. Nova Iorque: New York Press, 1989. KULFAS, M.; PORTA, F.; RAMOS, A. Inversión extranjera y empresas transnacionales en la economía argentina, Buenos Aires, Serie Estudios y Perspectivas, n. 10, ECLAC, 2002.

LEITE, M. P. Desenvolvimento econômico local e descentralização na América Latina: a experiência da Câmara regional do Grande ABC no Brasil. Santiago de Chile: Comisión Económica para América Latina y el Caribe (CEPAL), 2000.

LIJPHART, A. Comparative politics and the comparative method. American political science review. v. 65, n. 03, p. 682-693, (s/l), 1971.

LIMA, R. Açúcar, Coca-Cola e automóveis: ação político-empresarial na construção de um "município modelo" em Porto Real (RJ). 2005.181 f. Dissertação (Mestrado em Sociologia e Antropologia). Universidade Federal do Rio de Janeiro, Rio de Janeiro, 2005.

LIPIETZ, A. O fordismo periférico. Ensaios FEE. Porto Alegre, v. 2, n.10, 1989.

LUKACS, L. P. Evolução dos sistemas de produção: Ford Amazon na Bahia. 2005. 102 f. Dissertação (Mestrado em Administração). Universidade Federal da Bahia, Salvador, 2005.

MARKUSEN, A. Áreas de atração de investimentos em um espaço econômico cambiante: uma tipologia de distritos industriais. Nova economia. v. 5, n. 2, p. 9-44, 1995.

MARTIN, S. As câmaras setoriais e o mesocorporativismo. Lua Nova, v. 37, p. 139-170, 1996.

MARTIN, S. B.; VEIGA, J. P. Globalização dos mercados, localização produtiva e relações in-terfirmas: o caso das montadoras alemãs nos EUA nos anos 1990. In: NABUCO, M.; NEVES, M.; CARVALHO NETO, A. Indústria automotiva: a nova geografia do setor produtivo. Rio de Janeiro: DP\&A, 2002.

MENDES, V. M. O. A problemática do desenvolvimento em Salvador: Análise dos planos e práticas da segunda metade do século XX (1950-2000). 2006. 274 f. Tese (Doutorado em Planejamento urbano e regional) - Programa de Pós-Graduação em Planejamento Urbano e Regional, Universidade Federal do Rio de Janeiro, Rio de Janeiro, 2006.

MYRDAL, G. Teoria econômica e regiões subdesenvolvidas. Minas Gerais: Editora Saga, 1960.

NABUCO, M.; NEVES, M.; CARVALHO NETO, A. Indústria automotiva: a nova geografia do setor produtivo. Rio de Janeiro: DP\&A, 2002.

NOVICK, M. Nuevas reglas de juego en la Argentina, competitividad y actores sindicales In: TOLEDO, . Enrique de la Garza (ORG.). Los Sindicatos frente a los procesos de transitión política. Buenos Aires: CILA/CLACSO/Asdi, 2001. OLIVEIRA, F.; COMIN, A. Apocalypse Now: o 'Coração das Trevas' do neoliberalismo. Os Cavaleiros do Anti-Apocalipse. Trabalho e Política na Indústria Automobilística. São Paulo, Entrelivros/Cebrap, 1999. OLIVERA, G. Implicaciones económico-territoriales del auge exportador mexicano. Estudios Demográficos y urbanos, p. 375-413, 2001. 
PAASI, A. Re-constructing regions and regional identity. In: Nethur Lecture, Nijmegen, 2000.

PESSOTI, B. C.; PESSOTI, G. C. A economia baiana e o desenvolvimento industrial: uma análise do período 19782010. In: Revista de Desenvolvimento Econômico. Salvador, v. 28, n. 22, dez. 2010.

PINTO, L. A. C. Sociologia e desenvolvimento: temas e problemas de nosso tempo. Rio de Janeiro: Civilização Brasileira, 1963.

RADOSEVIC, S.; ROZEIK, A. Foreign direct investment and restructuring in the automotive industry in Central and East Europe. Working Paper. n. 53. Londres: University College London, 2005.

RAMALHO, J. R. Novas conjunturas industriais e participação local em estratégias de desenvolvimento. Revista Dados. Rio de Janeiro, v. 48, n. 3, 2005.

"Novas fábricas, velhas práticas: relações trabalhistas e sindicais na indústria automobilística brasileira." Caderno CRH 17. n. 41, 2006.

SANTANA, M. A. Ruptura geracional induzida e estratégias de gestão: a experiência nas montadoras do sul fluminense. Revista Educação e Sociedade. Campinas, v. 31, n. 111, 2010.

SASSEN, Saskia: The mobility of capital and labour. Cambridge: Cambridge University Press, 1988.

SUNKEL, O.; PAZ, P. O subdesenvolvimento latino-americano e a teoria do desenvolvimento. Rio de Janeiro: Forum, 1974.

TORRES, R.L.; CÁRIO, S.A.F. O mito da industrialização como desenvolvimento: O comando do excedente na cadeia mercantil da indústria automobilística brasileira (s/i), 2013.

VAN TULDER, R.; RUIGROK, W. European cross-national production networks in the auto industry: Eastern Europe as the low end of European car complex. Berkeley roundtable on the international economy. 1998.

VEGA, M. C. El desarrollo de la industria de la maquila en México. Problemas del Desarrollo. Revista Latinoamericana de Economía. v. 35, n. 138, 2004.

Recebido em: 16/01/2018

Aceito em: 31/03/2018 